TABLE VI-Infants at Risk: Analysis of Readmissions and Deaths in 264 Group 1 Babies

\begin{tabular}{|c|c|c|c|c|}
\hline Risk Factors & No. $(\%)$ of Infants & No. (\%) Readmitted & No. $(\%)$ of Deaths & Comment \\
\hline $\begin{array}{l}\text { Twin } \\
\text { Discharged in June/July }\end{array}$ & $\begin{array}{l}53(20 \cdot 1) \\
33(12 \cdot 5)\end{array}$ & $\begin{array}{l}11(20 \cdot 8) \\
15(45 \cdot 5)\end{array}$ & $\begin{array}{r}7(13 \cdot 2) \\
10(30 \cdot 3)\end{array}$ & $\begin{array}{l}\text { Smaller twin neglected } \\
\text { Temperature }\left({ }^{\circ} \mathrm{C}\right) \text { June } 3.4 \text { (min.)-23.4 (max.) } \\
\text { July } 1.3 \text { (min.)-25.8 (max.) }\end{array}$ \\
\hline Hypothermia & $14(5 \cdot 3)$ & $14(100)$ & $9(64 \cdot 3)$ & Inadequate subcutaneous fat or clothing \\
\hline
\end{tabular}

cold weather, with concurrent hypothermia, was associated with a high morbidity and mortality.

\section{Discussion}

The custom of keeping newborn babies of low birth weight in hospital until they achieve the traditional $2500-\mathrm{g}$ weight usually accepted as being adequate for discharge has been questioned over the past five years (Berg et al., 1969; Bauer and Tinklepaugh, 1971; Jefferson County, 1971; Dillard and Korones, 1973). In developed countries "physiological stability and parental adequacy" are the basic requirements to be met before discharge, almost independent of discharge weight (Berg and Salisbury, 1971). Readmission rates for babies discharged in such countries at weights over $2000 \mathrm{~g}$ have been about $5 \%$, while mortality after discharge has generally been less than $1 \%$. The advantages put forward for an "early discharge" policy in the U.S.A. apply even more so to underdeveloped communities. Lengthened hospital stay gives rise to overcrowded nurseries with a concommitant, and often high, incidence of and mortality from infection, particularly gastroenteritis; the smaller the baby the greater the risk. Furthermore, the costeffectiveness of an early discharge policy may be regarded only with favour in any country, hospital costs being what they are. Though such a policy has been practised in the past in some underdeveloped areas (Roman, 1965; S. Wayburne, personal communication) no prospective data exist as to its effectiveness and safety when dealing with mothers whose educational backgrounds are minimal, financial resources limited, and home environments far from the best. In Africa, however, there is one major advantage: most mothers, particularly in non-industrialized areas, breast feed their babies, often doing so adequately even when the babies weigh as little as $1600 \mathrm{~g}$.

Our results strongly suggest that, provided reasonable clinic and/or home visit back-up is available, babies who weigh more than $1900 \mathrm{~g}$ can safely be discharged from nurseries irrespective of parental education, socioeconomic status of the family, or season. Weight gain after discharge, morbidity, and mortality in our series compared favourably with that found in nurseries in the U.S.A. (Vaughan et al., 1969; Cohen and Dancis, 1948).
Furthermore, no overall differences in these values were detected between groups 2 and 3 . As a group the overall daily weight gain of group 1 was good provided adequate follow-up facilities were available. Though morbidity and mortality rates were raised as compared with the U.S.A. $(9 \% v .5 \%$ and $6 \% v$. $2 \%$ respectively) the babies in this group were much smaller, they were born to a group of mothers at risk, and their neonatal mortality rate ( 35 per 1000 live births) was far greater than reported rates for teaching hospitals in the U.S.A. Equally, infant mortality in the area is still by no means insignificant (227 per 1000 live births-Central Statistical Office, 1973). If the discharge policy was modified so that during the winter months babies were discharged only when their weights were above $1900 \mathrm{~g}$ and twins in general were not discharged below this weight morbidity and mortality rates for all the groups, including group 1, would become acceptable, even in comparison to rates for upper socioeconomic and industrialized communities.

We thank Dr. T. Stamps, Medical Officer of Health for the city of Salisbury; Sisters Earwood, Kachidza, and Nkiwani; and the nursing staff of all the municipal clinics, without whose co-operation this study could not have been undertaken. We also thank Dr. W. Castle for statistical help and Dr. M. Webster, Secretary for Health, for permission to report the findings.

Requests for reprints should be addressed to Professor J. Wolfsdorf, Department of Paediatrics and Child Health, Harari Central Hospital, Box ST 494, Southerton, Salisbury, Rhodesia.

\section{References}

Bauer, C. H., and Tinklepaugh, W. (1971). Clinical Pediatrics, 10, 467. Berg, R. B., Salisbury, A. J., and Kahan, R. (1969). Fournal of the American Medical Association, 210, 1892.

Berg, R. B., and Salisbury, A. J. (1971). American fournal of Diseases of Childhood, 122, 414 .

Central Statistical Office. (1973). Monthly Digest of Statistics. Salisbury, Rhodesian Government Printer.

Cohen, J. J., and Dancis, J. (1948). Fournal of Pediatrics, 33, 564

Dillard, R. G. and Korones, S. B. (1973). New England fournal of Medicine, 288, 131 .

Jefferson County. (1971). Fournal of Arkansas Medical Society, 68, 168.

Roman, C. (1965). Revista Chilena de Pediatria, 36, 438.

Vaughan, V. C. (1969). In Textbook of Pediatrics, ed. W. E. Nelson, V. C. Vaughan III, and R. J. McKay, p. 22. Philadelphia, Saunders.

\title{
Persistent Primary Enuresis: A Urodynamic Assessment
}

\section{G. WHITESIDE, E. P. ARNOLD}

British Medical fournal, 1975, 1, 364-367

\section{Summary}

Videocystourethrography with synchronous pressure and flow-rate recordings has been carried out on 50 patients

\section{Middlesex Hospital, London W1N 8AA}

C. G. WHITESIDE, B.M., F.F.R., Consultant Radiologist

E. P. ARNOLD, M.B., F.R.C.S., Clinical Research Fellow, Department of Neurology and Urology (Now Senior Lecturer in Urology, University of Otago, Dunedin, New Zealand) referred for the investigation of persistent primary enuresis. Urodynamic studies showed nocturnal enuresis to be associated mainly with normal detrusor function and nocturnal plus diurnal enuresis mainly with abnormal detrusor function. Evidence is presented which suggests that these two distinct types of enuresis occur de novo and do not overlap. Out of 18 formerly enuretic male patients nine with abnormal detrusor function showed persistent nocturnal plus diurnal symptoms.

\section{Introduction}

The term enuresis means bed-wetting during sleep and does not 
indicate any underlying cause. Primary enuresis refers to bedwetting since birth to beyond the age of 6 in the absence of urinary infections, structural abnormalities of the urinary tract, or overt neurological disorders.

Urinary tract disorders are rarely the sole cause of enuresis. While it is a matter of clinical judgement to determine the extent of investigations required in any individual case, exclusion of urinary infection and impairment of renal function are primary considerations. Overt neurological disease and bladder outflow obstruction must also be excluded before a patient can truly be regarded as a primary enuretic.

The purpose of this paper is to show that a large number of patients who fulfil the above criteria for primary enuresis prove on urodynamic investigation to have an underlying abnormality of bladder function. Furthermore, many of these patients exhibit a diurnal pattern of urgency (often with incontinence) and frequency, finding it difficult to hold their water for more than a short time. Other cases show no abnormality of micturition by day. Clinically, therefore, they can be divided into nocturnal plus diurnal and nocturnal enuretics respectively (Kolvin and Taunch, 1973).

\section{Patients and Methods}

Fifty patients (23 male and 27 female) aged 6 to 49 (mean 22) years were referred to the urodynamic clinic for investigation of persistent primary enuresis; 13 were nocturnal and 37 diurnal plus nocturnal enuretics. The number of "dry" nights varied but no patient had been dry for more than a month. One patient had periodic bouts corresponding with menstruation. Two others had a history of quiescent periods lasting one month and two years followed by recurrent enuresis.

Each patient was examined by synchronous combined videocystography with pressure and flow studies using the technique of Bates and Corney (1971). Filling and postural cystometry was an integral part of the procedure (Arnold, 1974). Since the technique requires urethral catheterization only two of the 15 patients aged 6 to 16 years were boys. The series was highly selective and in no way represents a normal spectrum of patients. All showed a normal flow rate and emptied to completion.

\section{Results}

In 12 of the 50 patients the filling and postural cystometrogram, voiding pressure, flow rate, and cystographic appearances were all normal (fig. 1). Of the remaining 38 patients 30 showed abnormalities of supine filling, the pressure rising excessively (above $10 \mathrm{~cm}$ of water; Arnold, 1974) or waves of uninhibited systolic contractions being recorded (fig. 2), and 8 showed

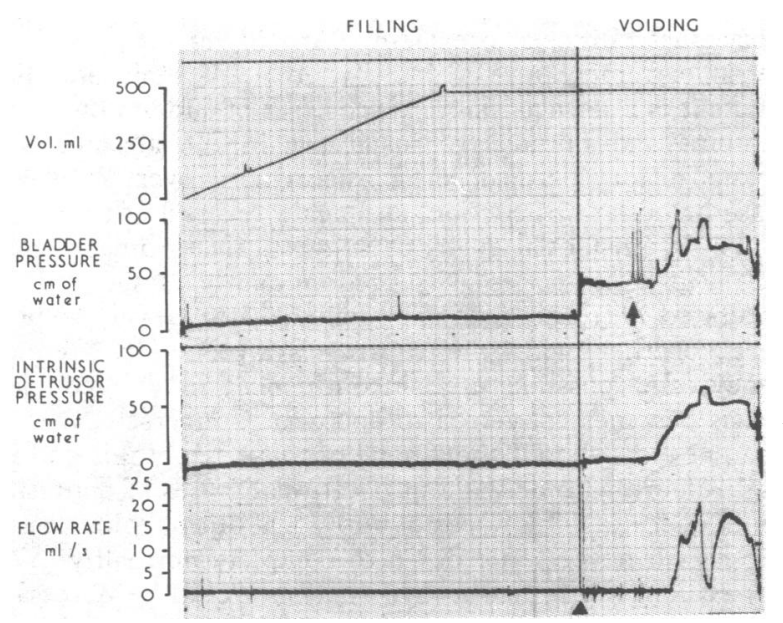

FIG. 1-Example of normal supine filling cystometrogram $(450 \mathrm{ml})$. On standing $(\Lambda)$ and coughing $(\boldsymbol{\uparrow})$ bladder pressure rises but intrinsic (detrusor) pressure remains unchanged until voiding begins. normal supine filling but with contractions either on postural change, during erect filling, or both.

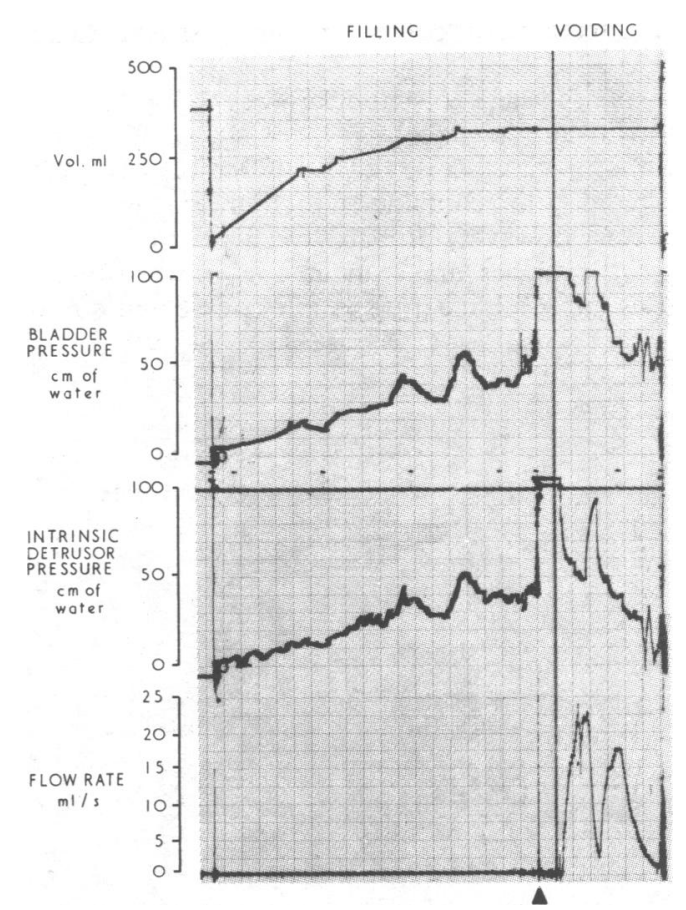

FIG. 2-Example of abnormal steep and systolic filling cystometrogram (325 ml). On standing (A) further isometric contraction occurs and is maintained until voiding begins, when pressure falls dramatically; interruption of voiding causes further large isometric contraction. "Primary systolic pattern;" compare with fig. 1 .

Of the 38 patients with abnormalities 12 showed a distinctive pattern ("primary systolic pattern")-namely, a systolic rise in pressure during filling and a further isometric contraction to a pressure of over $100 \mathrm{~cm}$ of water on standing, the patient holding on with the external sphincter. When voiding, the sphincter relaxes while the isotonic pressure falls sharply as the flow reaches its maximum; when the flow is voluntarily interrupted by closing the distal sphincter the isometric detrusor pressure kicks back vigorously to its original high level, falling dramatically as micturition is resumed (fig. 2).

Any bladder which in the absence of neurological disease exhibits uninhibited contractions which the patient cannot abolish has been termed "unstable" (Bates, 1971) and is usually accompanied by frequency, nocturia, and urgency with urge incontinence. The prevalence of instability in the 13 nocturnal and 37 diurnal plus nocturnal cases is shown in fig. 3. The

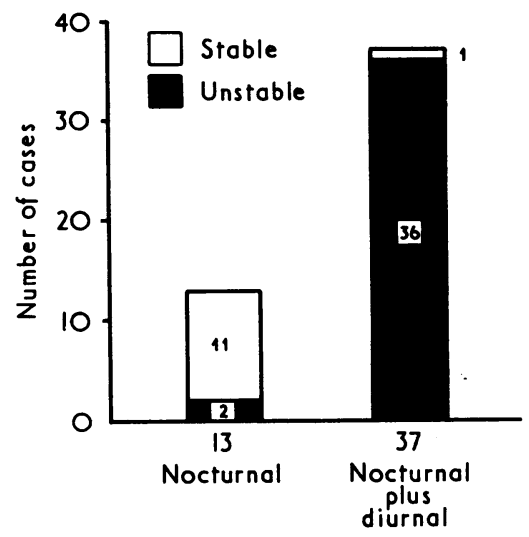

FIG. 3-Prevalence of bladder instability in two types of primary enuresis. 
findings suggest a strong association between abnormal detrusor behaviour and diurnal plus nocturnal enuresis. Trabeculation of the bladder was common in the unstable group, presumably due to uninhibited contractions occurring against a closed external sphincter with corresponding detrusor hypertrophy (Yeates, 1973).

Analysis of the age distribution of the patients showed stability and instability at all ages (fig. 4), suggesting that the two types of enuresis exist de novo. Intractable cases which had persisted into adult life contained a high proportion with bladder instability; this, however, probably resulted from the fact that mainly hard-core cases are seen at our clinic. Most cases of child enuresis, after all, clear up in due course and do not recur.

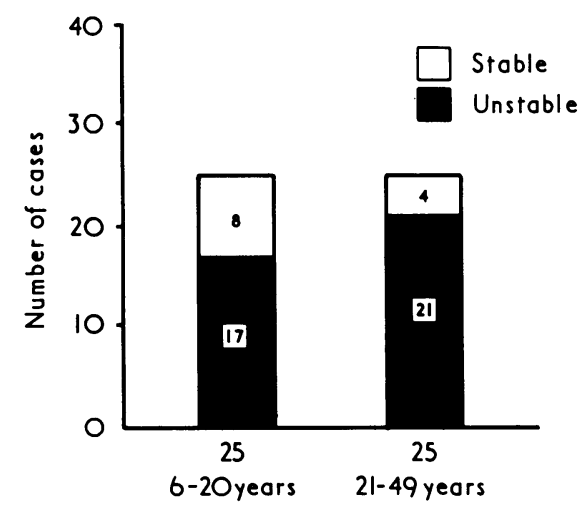

FIG. 4-Prevalence of bladder instability according to age. The four subjects aged 21 to 49 years with stable bladders were male.

\section{PREVIOUS HISTORY OF ENURESIS}

Further information was obtained by analysing 18 men with previous history of primary enuresis. Their average age was 37 years (range 18-71 years) and the average age at which enuresis had stopped was 12 years (range 7-20 years). The symptoms in this group were composed of frequency, nocturia, urgency, and incontinence (12); frequency only (2); and other symptoms (4). The urodynamic findings are shown in the table together with the patients' assessment of whether their present symptoms began immediately after the cessation of the enuresis. Three

Urodynamic Findings in 18 Men with Previous History of Primary Enuresis and Subjective Assessment of How Soon after Enuresis Stopped Present Symptoms Began. Figures are Numbers of Patients

\begin{tabular}{|c|c|c|c|c|c|c|}
\hline & & & $\begin{array}{c}\text { A } \\
\text { Frequency, } \\
\text { Nocturia, } \\
\text { Urge } \\
\text { Incontinence } \\
(\mathbf{n}=12)\end{array}$ & $\begin{array}{c}\text { B } \\
\substack{\text { Frequency } \\
\text { Only } \\
(n=2)}\end{array}$ & $\begin{array}{c}\text { C } \\
\text { Other } \\
(n=4)\end{array}$ & $\begin{array}{c}\text { Total } \\
(\mathbf{n}=18)\end{array}$ \\
\hline $\begin{array}{l}\text { Stable } \\
\text { Unstable }\end{array}$ & 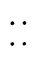 & $\therefore$ & $\begin{array}{r}0 \\
12\end{array}$ & $\begin{array}{l}2 \\
0\end{array}$ & $\frac{1}{3}$ & $\begin{array}{r}3 \\
15\end{array}$ \\
\hline \multicolumn{2}{|c|}{$\begin{array}{l}\text { Immediate onset } \\
\text { Delayed onset .. }\end{array}$} & $\because$ & $\begin{array}{l}9 \\
3\end{array}$ & $\begin{array}{l}0 \\
2\end{array}$ & $\begin{array}{l}0 \\
4\end{array}$ & $\begin{array}{l}9 \\
9\end{array}$ \\
\hline
\end{tabular}

patients developed nocturnal plus diurnal symptoms well after the enuresis had stopped; two were 71 years of age, their enuresis having ceased at 11 and 14 years respectively, and third was a man of 27 whose symptoms of frequency, nocturia, and urge incontinence had begun four months previously, his enuresis having ceased at age 11 . All the unstable cases had an abnormal supine filling cystometrogram and four showed a primary systolic pattern (two in column A and two in column C). Even this male series was highly selective as only those with subsequent micturition disorders are seen at our clinic.

In female ex-enuretics the findings were similar but analysis was complicated by other causes of frequency, nocturia, and urgency such as recurrent infections, urethrotrigonitis, and the urethral syndrome (which are not usually associated with unstable bladders) and also by the incontinence problems common to this sex.

\section{FAMILIAL INFLUENCE}

It is well known that enuresis runs in families. Our series included a pair of identical twin girls aged 8 who were both nocturnal plus diurnal (unstable) enuretics and whose father was similarly affected. Monozygotic twins are more concordantly affected than dyzygotic (Bakwin, 1973), and curiously enough the genetic influence appears to be stronger in nocturnal than diurnal cases (Hallgren, 1957).

\section{REDUCED FUNCTIONAL BLADDER CAPACITY}

Several workers have shown a reduced functional bladder capacity in enuretic children. This is due to the occurrence of uninhibited detrusor contractions (Linderholm, 1966). The true capacity under a general anaesthetic is the same as for nonenuretic children (Troup and Hodgson, 1971). In our series the mean filling capacity of 35 adults was $582 \mathrm{ml}$ in eight stable cases (range $350-1200 \mathrm{ml}$ ) and $326 \mathrm{ml}$ in 27 unstable cases (range 100$650 \mathrm{ml}$ ). The detrusor instability with reduced functional bladder capacity may lead not only to enuresis or nocturia but also to daytime frequency, urgency, and, not infrequently, urge incontinence. Vesicoureteric reflux was present in only two of our patients who were still enuretic and can scarcely be considered a factor in reducing functional bladder capacity except in a minor and static way. The theory that enuretics excrete abnormally large volumes of urine at night (Poulton and Hinden, 1953) was firmly refuted by Mills (1951) and Vulliamy (1956). Mills found that the day to night ratio of urine production was $2: 1$ in both enuretic and non-enuretic children.

\section{Discussion}

Patients are referred to our urodynamic clinic for the investigation of a wide variety of conditions, and observations relating to bladder neck and prostatic obstruction (Turner Warwick et al., 1973) and to female incontinence (Bates, 1971; Whiteside, 1972) have been recorded elsewhere together with the relevance of detrusor instability to these conditions. The symptoms relative to detrusor uninhibited contractions have also been recorded (Arnold et al., 1973; Turner Warwick et al., 1973).

Conversion from instability to stability of the bladder is rare except in outlet obstruction in males (Turner Warwick et al., 1973). In incontinent female patients with a negative enuretic history instability is prevalent (Arnold et al., 1973) and reversal extremely rare. Similarly, in adult male and female patients it is not uncommon to see cases of sudden onset of the symptoms and findings of instability in the absence of any previous history of disordered micturition, overt neurological disease or outlet obstruction, and again reversal of this is rare.

This circumstantial evidence suggests that primary enuresis which (in this series) is predominantly associated with uninhibited detrusor behaviour will tend to persist somewhat longer together with the diurnal symptoms of frequency, urgency, and possible urge incontinence; in due course the enuresis becomes converted to nocturia. Conversely, the stable nocturnal cases should show none of these symptoms and reach complete cure with or without occasional lapses of enuresis but without nocturia. This does not imply that diurnal plus nocturnal enuresis will never settle down to complete normality (Yeates, 1973)-a long-term prospective analysis would be necessary to decide. All we can say at this stage is that patients with other conditions-for example, unstable female stress or urge incontinence without enuresis examined at intervals over 
several years have shown a persistence of their instability even when the symptoms have been improved by drugs or surgery (Arnold et al., 1973; Brown, 1973).

The treatment claimed to train the enuretic child to wake at night before passage of water occurs results in enuresis being replaced either by nocturia, which in diurnal plus nocturnal cases will be accompanied by frequency, urgency, and threatened urge incontinence, or, in nocturnal cases only, by complete cure. Our patients who had dry episodes confirmed this; a change of locus and environment may cause sudden temporary disappearance of nocturnal enuresis with subsequent return. "It never troubles me on holiday," remarked one of our male nocturnal enuretics aged 25 ; "when I go to camp with the school I am dry," said a 16-year-old girl with nocturnal enuresis. Both these patients were normal on urodynamic study and had no daytime symptoms.

\section{DEPTH OF SLEEP}

Not only does the enuretic child exhibit uninhibited detrusor contractions during sleep but these fail to arouse him sufficiently to enable him to avert threatened leakage by contracting the external sphincter before visiting the lavatory. Furthermore, most enuretic children remain asleep despite this detrusor contraction; nor are the majority woken by the discomfort of lying in a wet bed. This contrasts with a child who occasionally wets the bed as a result of psychological or environmental change and who usually does wake up on wetting. These observations appear to lend support to the suggestion that enuretics sleep more deeply than do normal children. Electroencephalographic studies indicate that the enuretic episode typically occurs during non-rapid-eye-movement (N.R.E.M.) sleep and begins at deeper levels of sleep when there is decreased function in the reticular activating system, as discussed by Martin (1971). At the deeper levels of N.R.E.M. sleep an increase in uninhibited spontaneous contractions has been shown. Nevertheless, the deep-sleep theory of enuresis received little support from controlled clinical research and experimental work
(Kolvin and Taunch, 1973). It seems, however, that in nocturnal plus diurnal (unstable) cases which it is hoped to convert to nocturia, alteration of the depth of sleep must be a factor in the success of any treatment.

\section{Conclusion}

Much of our thought has been stimulated by the work of many authors brought together in an excellent book (Kolvin et al., 1973) which showed that our urodynamic findings fitted in well with the clinical observations. Much remains unanswered and we can only hope that urodynamics will make a small contribution to our knowledge. Dynamic examinations of the type described are indicated only when enuresis is persistent or differentiation of the clinical type is difficult.

\section{References}

Arnold, E. P. (1974). Urologia Internationalis, 29, 185.

Arnold, E. P., et al. (1973). American fournal of Obstetrics and Gynecology, $117,805$.

Bakwin, H. (1973). In Bladder Control and Enuresis, ed. I. Kolvin, R. C. MacKeith, and S. R. Meadow, chap. 9. London, Heinemann.

Bates, C. P. (1971). Annals of the Royal College of Surgeons of England, 49, 18. Bates, C. P., and Corney, C. E. (1971). British fournal of Radiology, 44, 44. Brown, A. (1973). Aleck Bourne Lecture unpublished.

Hallgren, B. (1957). Acta Psychiatrica et Neurologica Scandinavica, Suppl. No. 114 .

Kolvin, J., MacKeith, R. C., and Meadow, S. R. (editors) (1973). Bladder Control and Enuresis. London, Heinemann.

Kolvin, L., and Taunch, J. (1973). In Bladder Control and Enuresis, ed. I. Kolvin, R. C. MacKeith, and S. R. Meadow, chap. 19. London, Heinemann.

Linderholm, B. E. (1966). Fournal of Urology, 96, 718.

Martin, G. I. (1971). American fournal of Diseases in Childhood, 122, 42.

Martin, G. . (1971). American fournal of Diseases

Poulton, E. M., and Hinden, E. (1953). Archives of Disease in Childhood, 28, 392 .

Troup, C. W., and Hodgson, N. B. (1971). Fournal of Urology, 105, 129.

Vulliamy, D. (1956). Archives of Disease in Childhood, 31, 439.

Warwick, R. T., et al. (1973). British Yournal of Urology, 45, 59, 631.

Whiteside, C. G. (1972). British Medical Bulletin, 28, 214

Yeates, W. K. (1973). In Bladder Control and Enuresis, ed. I. Kolvin R. C. MacKeith, and S. R. Meadow, chap. 18. London, Heinemann.

\title{
Measurement of Fibrinogen-Fibrin-related Antigen in Serum as Aid to Diagnosis of Deep Vein Thrombosis in Outpatients
}

\author{
D. A. TIBBUTT, \\ C. N. CHESTERMAN, \\ M. J. ALLINGTON, \\ E. W. WILLIAMS, \\ T. FAULKNER
}

British Medical fournal, 1975, 1, 367-369

\section{Summary}

A study of serum levels of fibrinogen-fibrin-related antigen (F.R.-antigen) in outpatients presenting with clinical features suggesting deep vein thrombosis was undertaken. A raised serum level of this antigen ( $\geqslant 12$ $\mathrm{mg} / \mathrm{l}$ ) is strong evidence in favour of the diagnosis of deep vein thrombosis. It is virtually conclusive evidence

\section{Radcliffe Infirmary, Oxford OX2 6HE}

D. A. TIBBUTT, B.M., M.R.C.P., Senior Medical Registrar

C. N. CHESTERMAN, D.PHIL., M.R.A.C.P., Lecturer in Haematology

M. J. ALLINGTON, D.PHIL., Principal Scientific Officer, Department of Haematology

E. W. WIILIAMS, M.B., F.F.R, Senior Registrar in Radiology

T. FAULKNER, M.B., D.M.R.D., Registrar in Radiology if other known causes of a raised level of the antigen are absent. On the other hand, a normal serum level of F.R.-antigen does not exclude even extensive thrombosis, and other objective techniques are required to substantiate the diagnosis.

\section{Introduction}

The diagnosis of deep vein thrombosis (D.V.T.) of the lower limb is notoriously difficult to make on clinical grounds alone, and for this reason ascending venography and the ${ }^{125} \mathrm{I}$-fibrinogen uptake test (Atkins and Hawkins, 1965; Kakkar et al., 1970) have become invaluable aids. Several attempts have been made to find a laboratory test which would identify patients with incipient or established venous thrombosis (Fletcher et al., 1972; Flute et al., 1972; Gurewich, 1972), but none have produced an investigation which is both simple and reliable. 